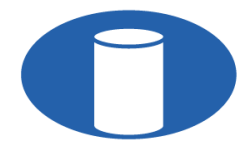

IBRACON Structures and Materials Journal

Revista IBRACON de Estruturas e Materiais

IBRACON

ISSN 1983-4195

ismj.org

ORIGINAL ARTICLE

\title{
Strain, natural frequency, damping coefficient and elastic modulus of mortar beams determined by fiber Bragg grating (FBG) sensors
}

\author{
Deformação específica, frequência natural, coeficiente de amortecimento e módulo \\ elástico de vigas de argamassa determinados por sensores em fibra ótica com rede \\ de Bragg (FBG)
}

Gustavo Macioski ${ }^{\mathrm{a}}$

Valmir de Oliveira ${ }^{\mathrm{b}}$

Marcelo Henrique Farias de Medeiros $^{\mathrm{a}}$

${ }^{a}$ Universidade Federal do Paraná - UFPR, Programa de Pós-graduação em Engenharia Civil - PPGEC, Curitiba, PR, Brasil

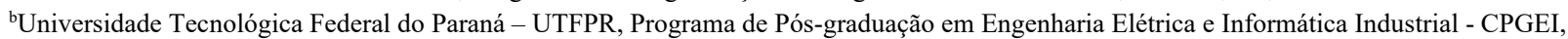

Curitiba, PR, Brasil

Received 17 June 2020

Accepted 11 September 2020

\begin{abstract}
Structural health monitoring can detect anomalies in time, allowing the implementation of more efficient maintenance and repair actions in special engineering structures. An alternative in the monitoring and evaluation of structures in civil engineering is the use of optical fibers inscribed with Bragg gratings (FBG or Fiber Bragg Grating). This paper aims to compare available techniques to estimate the elastic module of cementitious composites, as well as contribute to the application of optical fiber sensors in the monitoring of strain, natural vibration frequency, damping coefficient and elastic modulus of mortar beams. The FBG sensors manufactured and calibrated by the authors presented a good precision for measuring those parameters in mortar samples. The results show that FBG sensors and strain gauge sensors present a similar result for strain and estimation of the elastic module (static and dynamic), therefore, bare FBGs could be further investigated for non-destructive testing.
\end{abstract}

Keywords: modulus of elasticity, structural analysis, impulse excitation of vibration, non-destructive testing, optical fiber sensors.

Resumo: O monitoramento estrutural pode detectar anomalias no tempo, permitindo a implementação de ações de manutenção e reparação mais eficientes em estruturas de obras de arte. Uma alternativa no monitoramento e avaliação de estruturas em engenharia civil é a utilização de fibras óticas inscritas com redes de Bragg (FBG ou Fiber Bragg Grating). Este trabalho visa comparar as técnicas disponíveis para estimar o módulo elástico de compósitos cimentícios, bem como contribuir para a aplicação de sensores de fibra ótica na avaliação da tensão, frequência natural de vibração, coeficiente de amortecimento e módulo elástico de vigas de argamassa. Os sensores FBG fabricados e calibrados pelos autores apresentaram uma boa precisão na medição destes parâmetros em amostras de argamassa. Os resultados mostram que os sensores FBG e strain gauges apresentam resultados semelhantes para a deformação específica e estimativa do módulo elástico (estático e dinâmico), portanto, FBGs nuas poderiam ser investigadas mais detalhadamente em testes não-destrutivos.

Palavras-chave: módulo de elasticidade, análise estrutural, impulso de excitação de vibração, ensaio não destrutivo, sensores em fibra ótica.

How to cite: G. Macioski, V. Oliveira, and M. H. F. Medeiros, "Strain, natural frequency, damping coefficient and elastic modulus of mortar beams determined by fiber Bragg grating (FBG) sensors", Rev. IBRACON Estrut. Mater., vol. 14, no. 3, e14312, 2021,

https://doi.org/10.1590/S1983-41952021000300012

Corresponding author: Gustavo Macioski. E-mail: gmacioski@gmail.com

Financial support: This study was financed in part by the "Coordenação de Aperfeiçoamento de Pessoal de Nível Superior - Brasil (CAPES)" - Finance Code 001. Conflict of interest: Nothing to declare. 


\section{INTRODUCTION}

Young's modulus, elastic modulus or modulus of elasticity is a mechanical parameter that represents the stiffness of a solid material that can be affected by the material chemical composition, microstructure, and defects [1]-[5]. It can be obtained by the ratio of the requested normal stress to the specific deformation suffered by the material [6].

Determining this parameter is essential for the calculation of the serviceability requirements of structures defined by ACI 318 Building Code for concrete structure design [7] and other international structural standards. Mindess et al. [8] emphasize that from the elastic modulus it is possible to estimate the time of support removal during construction, check excessive deformation of beams and estimate decompression limits, crack opening and vibration frequency in structures. Thus, all structural analysis depends directly on the elastic modulus of materials. Although this parameter can be estimated from the compressive strength, the elastic modulus can also be obtained experimentally by quasi-static or dynamic tests.

In quasi-static tests, a load is uniformly applied over a section and the strain related to the load is measured during the destructive test [9]. This methodology is the most used for the characterization of elastic modulus in concrete and it is standardized by ASTM C469 [10].

The strain measurement during the static test is usually performed by strain gauges or displacement transducers during the test, such as LVDTs (inductive transducers) and dial indicators (mechanical transducers) [11]-[15]. Similarly, during compression testing, some authors have already used fiber Bragg grating sensors (FBGs) to monitor concrete strain to calculate static elastic modulus [16], [17]. FBGs are optical fiber-based sensors able to measure strain and temperature due to its light reflection properties [18], its inscribing process and measuring principle will be further explained.

For Mobley [19], in the dynamic tests, the aim is to evaluate the performance of the structures, thus enabling the safety evaluation and the elaboration or confirmation of existing mathematical models. In dynamic tests, the elastic modulus is determined from the wave ability to propagate within the material. Since this is a parameter that can be obtained in the same sample (nondestructive testing) over a certain period, the evaluation of the dynamic elastic modulus of concrete is widely used in the evaluation of concrete durability (diagnosis of infrastructure).

It is noteworthy that dynamic tests are not affected by creep since the vibration levels applied to the samples imply very low stresses [20]. For this reason, Mehta and Monteiro [21] consider the dynamic elastic modulus in concrete and mortars approximately equal to the tangent modulus at the origin of the stress-strain curve determined in the static test and, therefore, up to $30 \%$ higher than the static modulus obtained in compression tests. In dynamic methods, the determination of the elastic modulus depends directly on the isotropy of the material, the support conditions and the position of the actuators and receivers.

For dynamic testing in concrete, ASTM C597 [22] standardizes the pulse velocity method for obtaining its dynamic elastic modulus [15], [23]. While ASTM C215 [24] describes the determination of the dynamic modulus in cylindrical samples by forced excitation using accelerometers [11], [14].

Similarly, ASTM E1875 [25] and ASTM E1876 [26] standards describe a similar vibration test (for different geometries and materials) by forced excitation and resonance techniques, respectively. While the first method evaluates the damped frequency of the material after an impact, the second method detects the resonance phenomenon when the material is continuously excited at different frequencies [13], [27]. In ASTM E1875 [25] and ASTM E1876 [26] standards, the type of sensor to be used is not described. However, the frequency response shall be measured within $1 \mathrm{~Hz}$ precision.

Indentation techniques can also be applied to estimate the elastic modulus of materials due to a probe penetration on the surface of a sample. This test is usually performed on a small scale (nano and micro indentation); hence, it does not allow the evaluation of the elastic modulus of heterogeneous materials. However, the method has already been used in the evaluation of the elastic modulus of crystalline phases of Portland cement, for example [28]-[31].

Using FBG, some authors have already evaluated the deformation of structural elements [32]-[39], the stress distribution within the concrete [40] and corrosion processes [41]. Dynamic and vibration tests were already performed by FBG sensors [42]-[44]. However, no research was found in the literature to estimate the static modulus of concretes and mortars by non-destructive simple bending tests using FBG. Also, it was not possible to find researches that have used optical sensors to determine the dynamic elastic modulus of materials since those researches are focused on measuring only deformations and vibration frequencies.

Given the different testing methods available for determining the elastic modulus of a material, and the different types of sensors available, a study is required to verify the possibility of performing these tests using fiber Bragg gratings sensors (FBG). Also, there is a need to understand how different sensors such as the FBG can influence the final results for strain, 
natural frequency, damping coefficient and elastic modulus of materials. Table 1 shows the main contributions of this study and the methods and sensors already used by other authors [14], [17], [27], [33]-[37], [40], [45]-[55].

Table 1. Sensors applied to mortar and concrete monitoring.

\begin{tabular}{|c|c|c|c|c|c|}
\hline & $\begin{array}{c}\text { Dial indicator/ } \\
\text { LVDT }\end{array}$ & Strain gauge & FBG & Microphone & Accelerometer \\
\hline Displacement & $\square \bullet$ & & & & \\
\hline Strain & & $\square \bullet$ & $\square \bullet$ & & \\
\hline Frequency of vibration & & $\square \bullet$ & $\square \bullet$ & $\square \bullet$ & $\square \bullet$ \\
\hline Damping coefficient & & $\square \bullet$ & $\bullet$ & $\square \bullet$ & $\bullet$ \\
\hline Static modulus by bending & $\bullet$ & $\square \bullet$ & $\bullet$ & & \\
\hline Dynamic modulus & & $\bullet$ & $\bullet$ & $\square \bullet$ & $\square \bullet$ \\
\hline
\end{tabular}

$\square$ Literature review $\bullet$ This study

Thus, this paper aims to present the structural evaluation of mortar beams instrumented with different sensors, including FBG, for the determination of elastic modulus (static and dynamic). This research aims to contribute to the comparison of existing methods and validate the use of FBG as a sensor in the determination of parameters used in the characterization of materials and validation of structural designs, as well as in the diagnosis of existing structures.

\section{FIBER BRAGG GRATING (FBG)}

Optical fiber is a flexible and transparent filament made from extruded glass or plastic. Standard optical fiber has a diameter of a few micrometers $(125 \mu \mathrm{m})$, slightly larger than human hair, and it is often used as a conductor of coded light [56].

Optical fiber is made up of two main components: core and cladding. The cladding reflects the diffused light into the core, ensuring that light transmission through it has a minimal loss. Thus, light is maintained in the core through total internal reflection effect [57]. This makes the fiber act as a waveguide, transmitting light between the two ends.

Due to the diffraction phenomenon, it is possible to change the refractive index of the glass in specific sections periodically, creating an optical filter inside the fiber. This modification is possible due to the photosensitivity of the optical fiber, which allows a permanent change in the refractive index in the fiber core when exposed to ultraviolet (UV) light [53]. Although not fully understood, this phenomenon occurs due to the existence of defects related to the incorporation of germanium atoms in the glassy structure of optical fibers during their manufacture, which when exposed to UV radiation break their bonds and generate light absorption bands [58].

Some techniques allow the improvement of fiber photosensitivity such as increasing germanium concentration in the fiber core and the use of co-dopants as boron during their manufacture. Another technique also used is hydrogenation, which consists of exposing the fiber to hydrogen in a high-pressure chamber [18], [59].

After inscribing a Bragg grating in the optical fiber core, the material will develop the ability to reflect a specific wavelength as a function of the grating spacing created. The process of acquiring or interrogating an FBG is performed by connecting a broadband light into the fiber to monitor the optical spectrum of light transmitted or reflected by the FBG [60], as it can be seen in Figure 1.

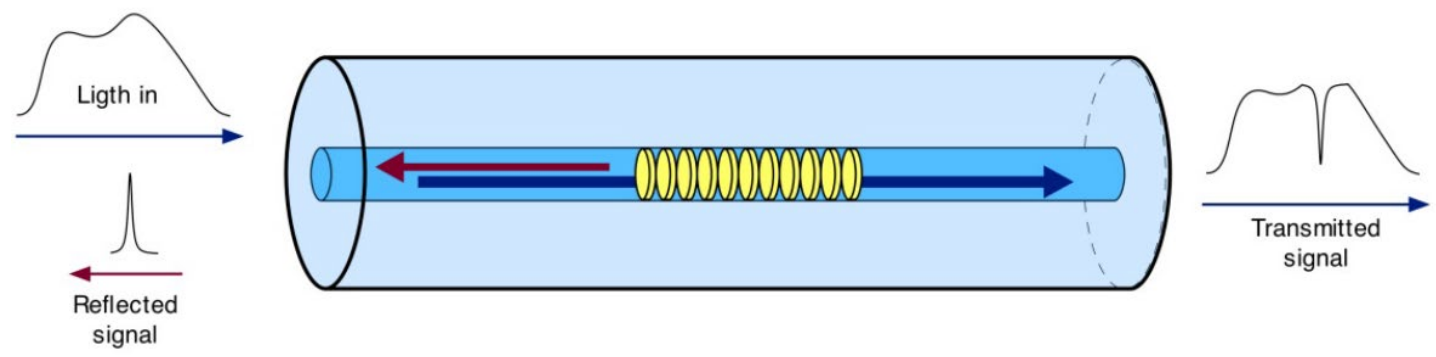

Figure 1. Transmitted and reflected signals during the interrogation of an FBG sensor [61] 
The peak wavelength that arises after the fabrication of an FBG sensor is described by Equation 1, where $\lambda_{B}$ is the Bragg wavelength (nm), $n_{e f}$ is the effective fiber core refractive index, and $\Lambda$ is half the spacing between phase mask grids $(\mathrm{nm})$ used during the inscribing process, known as the phase mask period [58].

$\lambda_{B}=2 . n_{e f} \cdot \Lambda$

From this light reflection property, the reflected signal can be calibrated for changes in the sensor. When the fiber undergoes axial deformations or temperature changes, there is a change in the microstructure spacing and, consequently, in the Bragg wavelength. There is also some variation in the refractive index from the photoelastic effect. These effects are independent for each existing FBG in a fiber optic segment. The strain $\Delta \varepsilon(\mu \mathrm{m} / \mathrm{m})$ and temperature $\Delta T\left({ }^{\circ} \mathrm{C}\right)$ sensitivity of an FBG sensor can be determined by the change in the wavelength spectrum $\Delta \lambda_{b}(\mathrm{~nm})$, as described by Equation $2[62]$.

$\frac{\Delta \lambda_{B}}{\lambda_{B}}=\left(1+p_{e}\right) \cdot \Delta \varepsilon+\left(\alpha_{A}+\alpha_{n}\right) \cdot \Delta T$

With $p_{e}$ being the photoelastic constant $(-0.212), \alpha_{A}$ is the thermo-optical coefficient $\left(8.3 \cdot 10^{-6 /{ }^{\circ}} \mathrm{C}\right)$ and $\alpha_{n}$ the coefficient of thermal expansion of the fiber $\left(0.55 \cdot 10^{-6 /}{ }^{\circ} \mathrm{C}\right)$ [63], [64].

\section{MATERIALS AND EXPERIMENTAL PROGRAM}

\section{FBG manufacturing}

For the manufacture of optical sensors, single-mode standard optical fiber (Draktel, SSMF G.652.D) with an effective refractive index of 1.468 was used. The inscribing was performed at a wavelength of $1540.9 \mathrm{~nm}$ using direct illumination by an ArF excimer laser (Coherent, Xantos XS model) operating at $193 \mathrm{~nm}$ with a frequency of $250 \mathrm{~Hz}$ and $1.5 \mathrm{~mJ} /$ pulse energy. The sensor manufacture is based on the diffraction of a UV beam emitted by a pulsed LASER using a phase mask (diffraction grating) to create a Bragg grating into the fiber core. During the inscribing process, a couple of mirrors are used to adjust the beam height and a cylindrical lens is used to focus the beam into the fiber core. Details on the manufacturing setup and inscribing process can be observed in Figure 2.

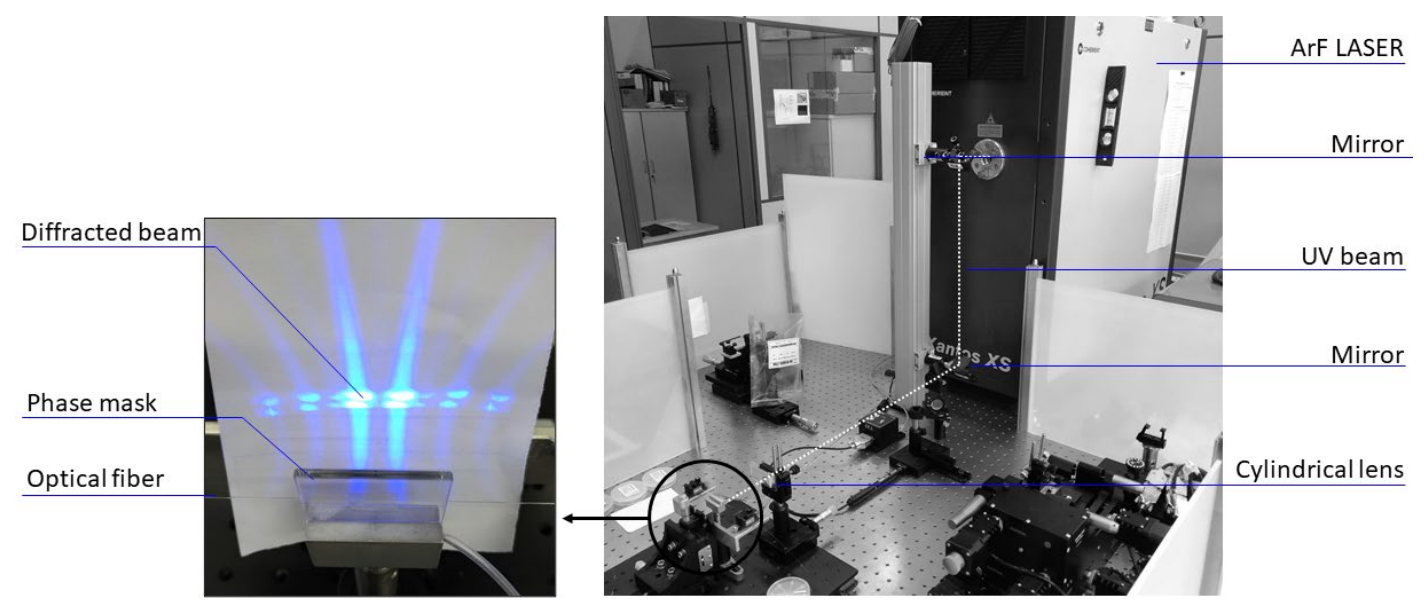

Figure 2. FBG inscribing process

After the FBG inscribing process, the FBG was calibrated according to its response to strain. A digital dial indicator (Mitutoyo, S1012M) was used in a servomotor apparatus for that purpose. The fibers were fixed to the metal ends of 
the apparatus using an epoxy glue with a drying period of 24 hours. For the calibration, ten wavelength measurements were made for each fiber deformation in three stretching cycles. The measurements were performed with the aid of an optical interrogator (MicronOptics, model SM-125).

\section{Specimen preparation}

For the evaluation of the structural elements, mortar prisms were molded using Portland cement type III according to ASTM C150 [65] classification and natural fine aggregate. The aggregate had a specific mass of $2.73 \pm 0.17 \mathrm{~g} / \mathrm{cm}^{3}$ according to ASTM C128 [66] and a fineness modulus of 2.36 according to ASTM C136 [67].

The mix design used was 1:2.75 by mass with water/cement ratio (w/c) of 0.485 ; the same composition used for Portland cement compressive strength characterization according to ASTM C109 [68]. Mortars were made using the procedures described by ASTM C305 [69] in a mechanical mixer. Three prismatic samples $(25 \times 25 \times 285) \mathrm{mm}$ were molded, demolded at $24 \mathrm{~h}$ and subjected to submerged cure in lime-saturated water at room temperature $\left(22^{\circ} \mathrm{C}\right)$ until the test age (28 days). Cylindrical specimens $(5 \times 10) \mathrm{cm}$ were also produced which presented, according to ASTM C39 [70], at 28 days, the mechanical compressive strength of $51.2 \mathrm{MPa}$. The test was performed in a hydraulic testing machine (EMIC, DL30000) after griding the surface of the samples.

\section{Instrumentation and calculations}

To determine the static and dynamic elastic modulus of the mortar beams, different sensors and techniques were employed. For this, at 28 days, the beams were crimped to allow a span length of $250 \mathrm{~mm}$. The cantilevered boundary condition was adopted because it can be used for all techniques and would produce equivalent results. Also, higher displacements and lower frequencies are obtained from this condition, allowing a higher precision on the measurements. Figure 3 shows the positioning of all sensors used in the mortar beam, although each sensor was used separately. For the static tests, five consecutive sample loads $(1,2,3,4$ and $5 \mathrm{~kg})$ were performed, and for each specimen, the tests were repeated 3 times.

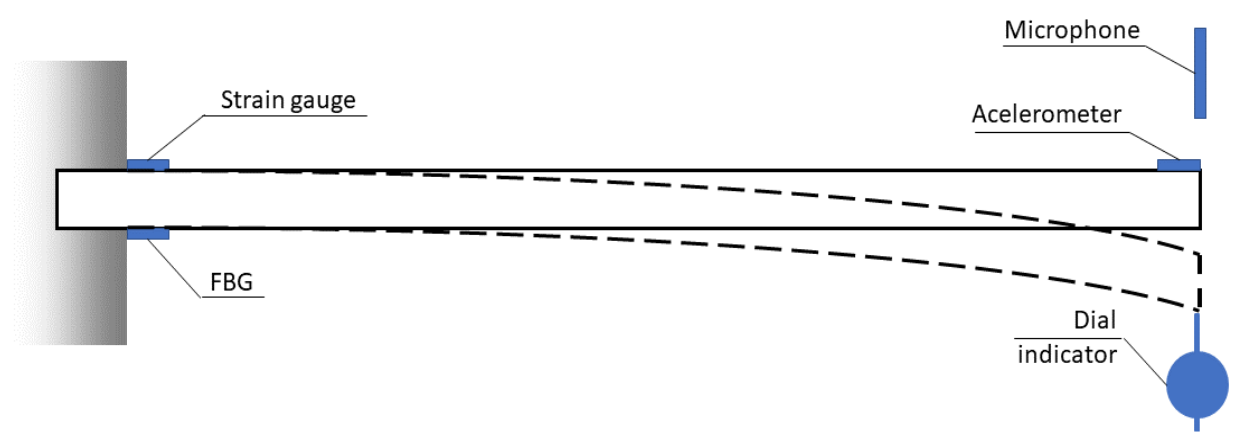

Figure 3. Cantilevered mortar beam and sensors

At the end of the beam, a digital dial indicator (Mitutoyo, S1012M) with a $0.01 \mu \mathrm{m}$ precision was positioned with the aid of a magnetic rod. By reading the beam vertical displacement $\delta(\mathrm{m})$ in the digital dial indicator it was possible to determine the static modulus $E(\mathrm{~Pa})$ by Equation 3 [71]. Where $P$ is the load $(\mathrm{N}), L$ the span length $(\mathrm{m})$ and $I$ the moment of inertia of the beam section $\left(\mathrm{m}^{4}\right)$.

$E=\frac{P \cdot L^{3}}{3 \cdot \delta \cdot I}$

Near to the beam support, strain gauge and FBG sensors were fixed. For the FBG sensor, initially, the acrylate layer from the fiber optic region was removed to ensure the adhesion between the fiber cladding and the resin. The optical fiber had to be placed slightly tensioned, allowing tensile and compression measurements in the sample. Therefore, one extremity of the sensor was glue, then the other end of the fiber was manually pulled (generating $2 \mathrm{~nm}$ displacements 
in the reflected spectrum) and the other end of the sensor was fixed. For this, a short drying period light-curable resin (Opallis Flow, FMG) was used. The FBG sensor installation and static loading can be seen in Figure 4. The acquisition of the FBG (reflected signal spectrum evaluation) data was performed by an optical interrogator (Microoptics, model SM-130). For the test, a sampling frequency of $1 \mathrm{kHz}$ was used.

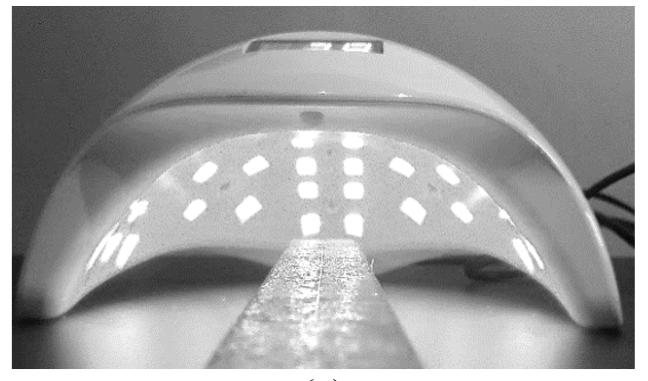

(a)

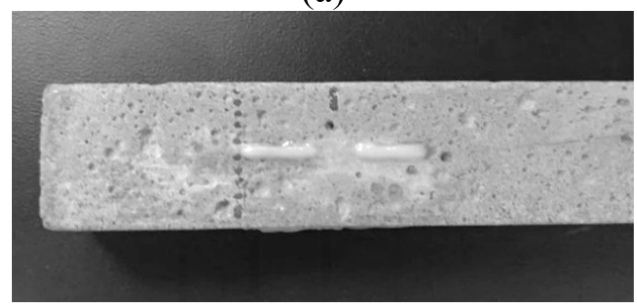

(b)

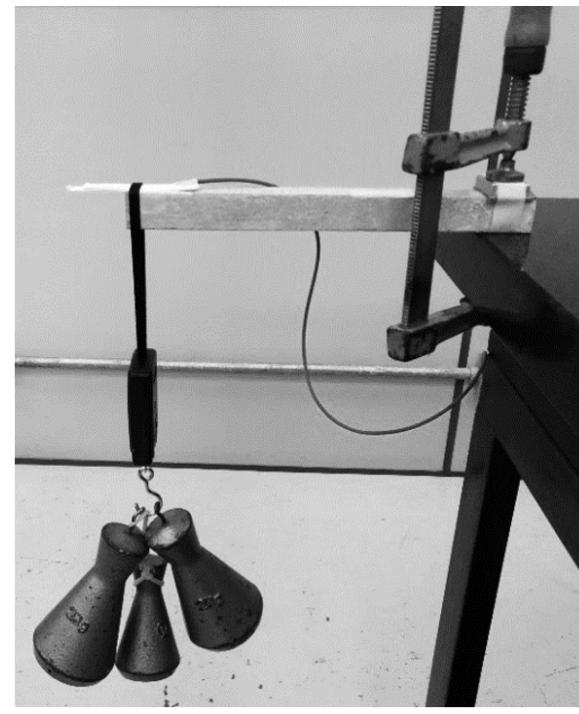

(c)

Figure 4. FBG instrumentation details: (a) resin UV curing, (b) final instrumentation and (c) cantilevered beam during static loadings

The linear grid strain gauge (Omega, model SGD-10/120-LY11), with $120 \Omega$ electrical resistance and a $10 \mathrm{~mm}$ grid, was fixed using cyanoacrylate glue all over its surface with a 24-hour drying time. The acquisition of its signal was performed in a data acquirer (Lynx, model ADS2000) with a sampling frequency of $1 \mathrm{kHz}$ that used a quarter-bridge circuit for signal balancing.

From the strain values obtained by the FBG and the strain gauge, it was possible to calculate the equivalent static elastic modulus $E(\mathrm{~Pa})$ from Equation 4 [71]. This equation was also used to estimate the specific strain equivalent to the vertical displacement recorded by the dial indicator. In Equation $4, P$ is the applied load $(\mathrm{N}), L$ the span length $(\mathrm{m}), b$ the section width $(\mathrm{m}), h$ the section height $(\mathrm{m})$ and $\varepsilon$ the measured strain $(\mathrm{m} / \mathrm{m})$. Since the strain $(\varepsilon)$ was measured a few millimeters from the crimp, the measured value at the center of the sensor was adjusted to the crimped point based on triangle similarity.

$E=\frac{6 \cdot P \cdot L}{b \cdot h^{2} \cdot \varepsilon}$

In addition to the strain gauge and FBG, the dynamic modulus was calculated using a high-precision accelerometer with a capacity up to 5 gravities (Kyowa, AS-5GB) connected to a data acquirer on a full-bridge circuit (Lynx, model ADS2000).

During the dynamic test, the beam was excited by a light tap its extremity using a $200 \mathrm{~g}$ metal bar according to ASTM E1875 [25], allowing it to go into dampened vibration with a temporal signal acquisition. It is noteworthy that the intensity of the excitation does not interfere with the frequency of vibration, material damping and the calculated elastic modulus. For each beam, the tests were also repeated 3 times.

After the acquisition, a Fast Fourier Transform (FFT) was performed, which converts the signal from the time domain to a representation in the frequency domain, allowing the natural vibration frequency of the material to be obtained. 
Using Equation 5, it was possible to calculate the dynamic elastic modulus. Where $E$ is the elastic modulus (Pa), $f_{l}$ is the natural vibration frequency for the first vibrational mode $(\mathrm{Hz}), \lambda_{I}$ is the constant of the first vibrational mode $\left(\lambda_{1}{ }^{2}=1.875^{2}\right), L$ is spam length (m), $I$ the moment of inertia $\left(\mathrm{m}^{4}\right)$ and $M$ the mass per meter or linear mass of the beam $(\mathrm{kg} / \mathrm{m})$.

$$
E=\frac{M}{I}\left(2 \cdot \pi \cdot f_{l} \cdot\left(\frac{L}{\lambda_{I}}\right)^{2}\right)^{2}
$$

The dynamic test was also performed on the SONELASTIC apparatus (ATCP Brand) following the requirements of ASTM E1876 [26] and ASTM C215 [24]. In the test, a directional microphone (CA-DP) is used to capture the acoustic pickup from the excited beam.

In this case, the intensity of a mechanical wave passing through the solid is acquired, and the dynamic modulus calculation follows Equation 6, described by ASTM E1876 [26]. In which, $E$ is the elastic modulus (Pa), $m$ the mass of the beam $(\mathrm{kg}), f_{l}$ the natural vibration frequency for the first vibration mode $(\mathrm{Hz}), b$ the section width $(\mathrm{m}), L$ the span length (m), $h$ the height of the section (m), $T_{l}$ the correction factor for prismatic geometry (-).

$$
E=0.9465 \cdot\left(\frac{m \cdot f_{1}^{2}}{b}\right) \cdot\left(\frac{L^{3}}{h^{3}}\right) \cdot T_{1}
$$

From the vibration tests, it was possible to calculate the damping coefficient of the mortar. The damping coefficient $\xi$ (-) was estimated by the logarithmic decrement method, according to Equation 7 [72]. In the equation, $A_{0}$ represents the initial amplitude and $A_{n}$ represents the amplitude (in the sensor measurement unit) after $n$ vibration cycles. For the calculation, the reading was always performed on the tenth oscillation of the damped wave.

$$
\xi=\frac{1}{2 \cdot \pi \cdot n} \cdot \ln \left(\frac{A_{0}}{A_{n}}\right)
$$

Finally, numerical modeling of the beam was performed to determine the theoretical strain near the support and the natural vibration frequency via finite element methods (FEM). This method was only used as a comparison basis to verify how experimental results would deviate from the theoretical model. For this, a finite shell element was used in a mesh with dimensions of $2 \mathrm{~mm}$ and the elastic modulus adopted was the one estimated by ACI 318 [7]. Usually, this method is used to estimate serviceability criteria in structure design and can be calculated by Equation 8 , where $f_{c k}$ is the characteristic compressive strength of concrete at 28 days $(\mathrm{Pa})$. Although there are several models for the estimation of the elastic modulus based on the concrete mechanical strength [27], the American building code requirements for structural concrete was adopted since this is the most widely used for structural design analysis. This model considers the compressive strength measured in cylindrical specimens for the estimation of the elastic module of the whole structure, including any slender beams.

$E=4700 \cdot \sqrt{f_{c k}}$

From the numerical simulation (FEM) it was possible to estimate in the cantilevered beam the theoretical strain near the support and vertical displacement at the end, as well as the theoretical natural frequency. Figure 5 presents a flowchart summarizing the tests and simulations performed and the parameters obtained for the calculation of the static and dynamic elastic modulus in this paper. 


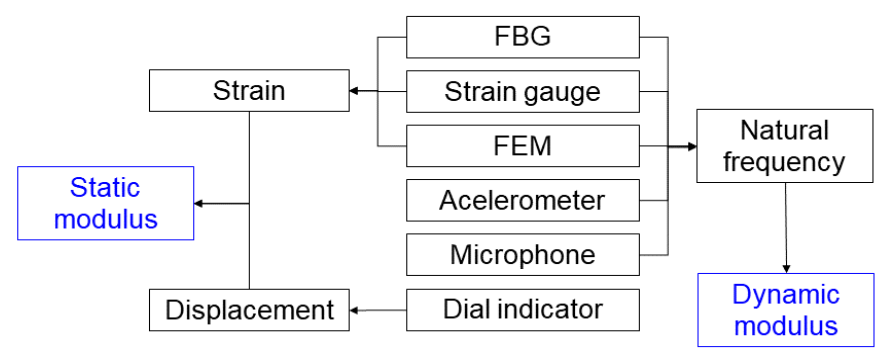

Figure 5. Evaluated techniques flowchart

\section{RESULTS AND DISCUSSION}

\section{FBG sensor calibration}

During the FBG calibration, the optical fiber was pulled on a metal apparatus and the strain was monitored by a dial indicator. Figure 6a shows the loading cycles and Figure $6 \mathrm{~b}$ shows the calibration of the FBG sensor.

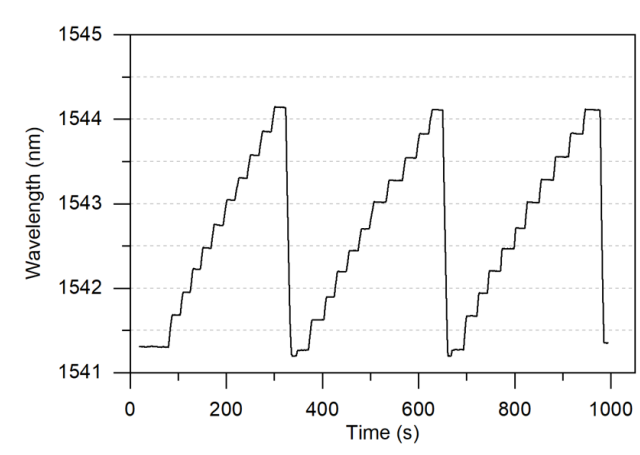

(a)

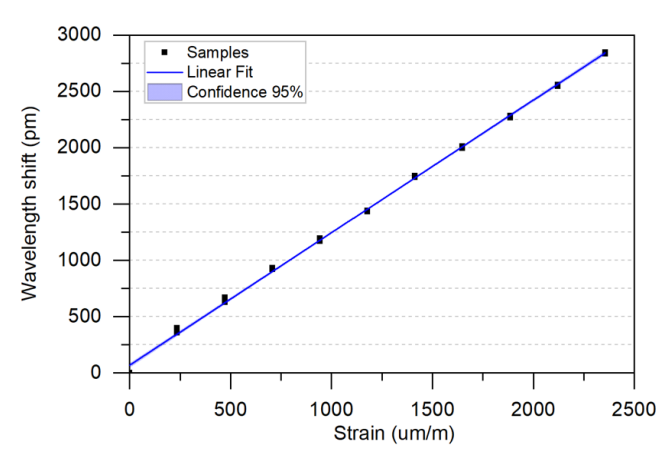

(b)

Figure 6. Sensor calibration: (a) Strain cycles during calibration and (b) FBG linear calibration

It is observed that during loading cycles there was no hysteresis (conservation of deformation after unloading) and no nonlinear variations in wavelength during calibration. After a linear adjustment, the FBG sensor had a sensitivity of $1.2180 \mathrm{pm} / \mu \mathrm{m} / \mathrm{m}$, or $1.2180 \mathrm{pm} / \varepsilon$, with an adjusted $\mathrm{R}^{2}$ of 0.9989 . Figure $6 \mathrm{~b}$ still shows the confidence interval of $95 \%$, which remained close to the linear adjustment.

From Equation 2, it is possible to estimate the theoretical calibration of the sensor. Therefore, considering the photoelastic fiber constant as -0.212 (the default value for single-mode fibers) and the recording length as $1540.9 \mathrm{~nm}$, the theoretical value of the wavelength variation as a function of the strain is $1.2142 \mathrm{pm} / \varepsilon$, result $0.31 \%$ lower than the experimental data obtained.

This variation is permissible and may be related to differences in fiber photoelastic properties or variations in effective fiber wavelength after the inscribing process. The value found for the strain sensitivity obtained for FBG is also close to values obtained or indicated by other authors [57], [58], [73]-[75]. Thus, the sensor presented a linear elastic behavior with low variation (mean error of $5 \mathrm{pm}$ ) in the readings, thus indicating a good precision for strain measurements in structural elements.

\section{Static modulus}

For the determination of the static elastic modulus, the mortar cantilevered beams were loaded at its end so that the sensor measurements could be performed. For the FBG test, it was possible to identify the displacement of the reflected spectrum by the optical sensor as a function of the loads applied, as shown in Figure 7. 


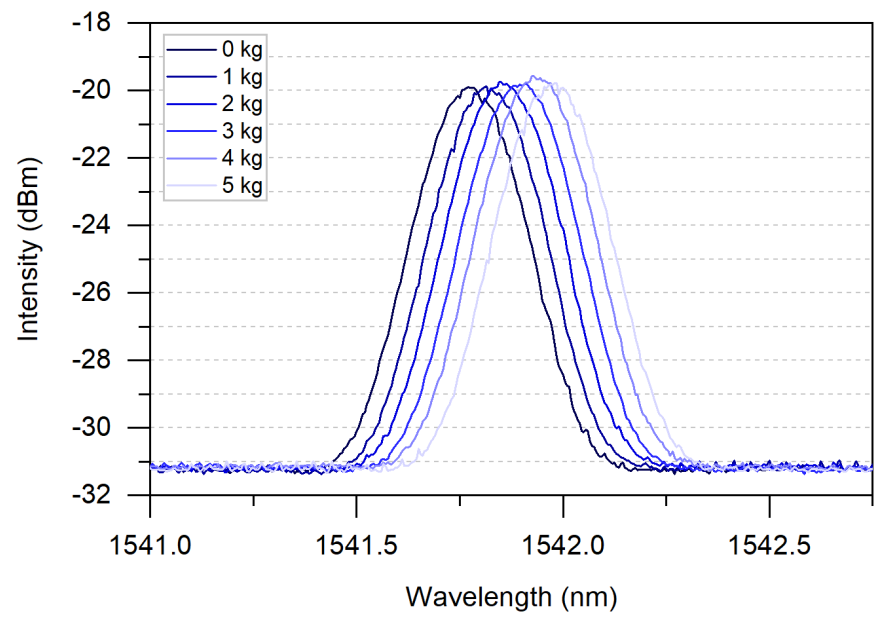

Figure 7. FBG reflected peak during loadings

As the load increased, the wavelength increased, as expected, due to the distancing of the Bragg grating. During the loading, there was no change in the spectrum shape, which averaged a full width at half maximum (FWHM) of $0.3205 \mathrm{~nm} \pm 0.0012 \mathrm{~nm}$ and reflected peak intensity of $11.702 \pm 0.035 \mathrm{dBm}$. In the FEM simulation, it was possible to verify the stress distribution along the beam length (Figure 8).

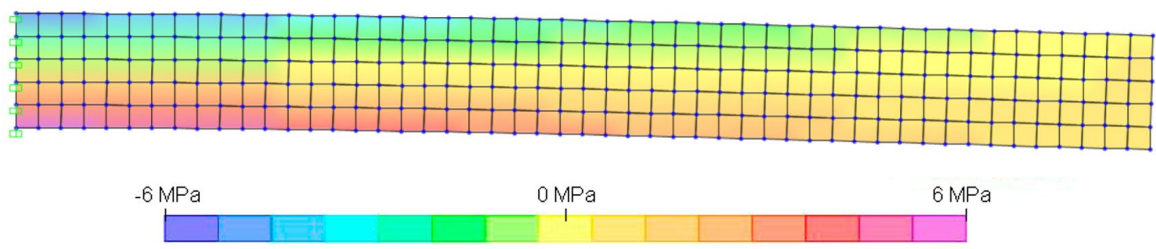

Figure 8. Beam stress distribution via FEM

In Figure 8, it is observed that there was an increase in the stress concentration near the beam support, with negative values (tensile) on the upper face and positive values (compression) on the lower face, symmetrically. From the results, it is noted that the mesh used to verify the stress distribution and beam deformations was adequate since the simulation presents a good stress distribution and it is possible to verify at different points the geometric properties of the element. With the measurements obtained by the dial indicator, FBG, strain gauge and FEM simulation, it was possible to compare the values of the strain obtained near the support, Figure 9.

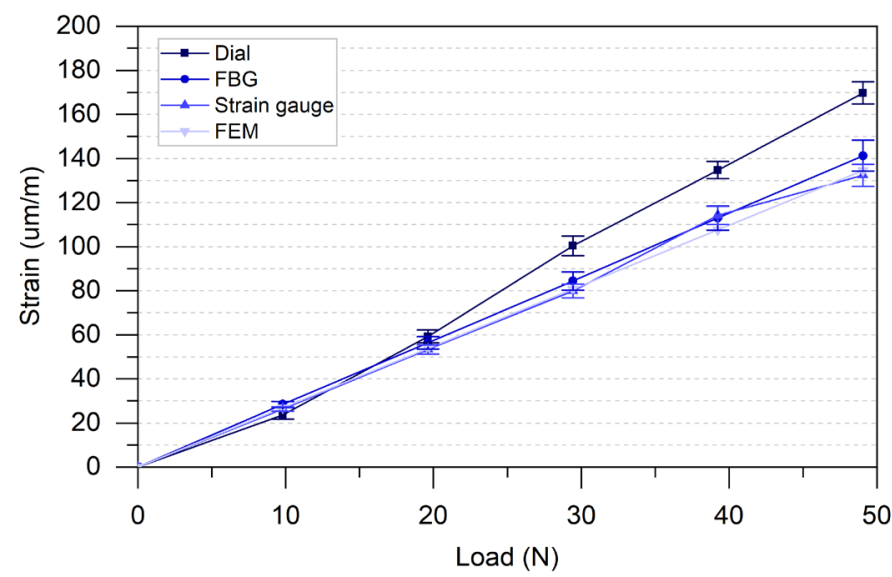

Figure 9. Strain measured by sensors 
During loading, only the dial indicator readings showed a slight deviation when compared to the other readings. It is noteworthy that the test performed with the dial indicator was the only methodology that evaluated the vertical displacement of the beam, while the others measured the strain itself. The dial indicator was also the only sensor that relied on the visual record of the readings. Although the sensor was positioned ensuring the perpendicularity between the beam and the sensor, Montija [76] states that readings with displacement transducers may vary due to the difficulty of guaranteeing the perpendicularity of the measuring rod to the monitored element, as well as that part of the sensor deforms during the readings. The comparison of the results obtained for the static elastic modulus of the mortar beams is presented in Figure 10.

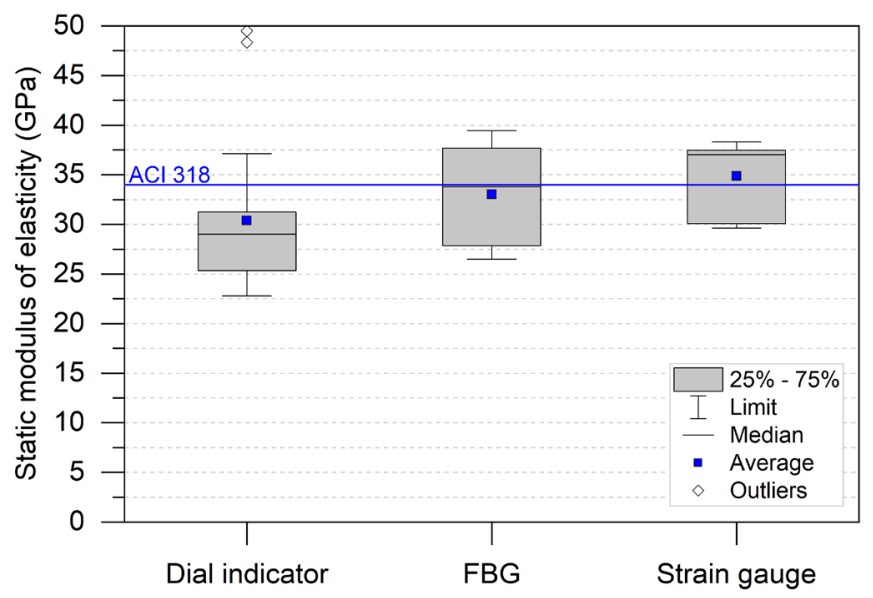

Figure 10. Static elastic modulus of the mortar beam

After performing an analysis of variance (ANOVA), at a significance level of 0.05 , it was possible to prove that the methods used influenced the elastic modulus values obtained. It was also observed, after means comparison by Tukey at a significance level of 0.05 , that there were no significant differences between the elastic modulus obtained by the FBG and the strain gauge. Thus, it can be stated that the dial indicator underestimated the elastic modulus by $10 \%$ when compared to the theoretical value estimated by ACI 318 [7] of $34.06 \mathrm{GPa}$.

The average value obtained by the FBG and the strain gauge was $33.95 \pm 0.59 \mathrm{GPa}$, a result $2 \%$ lower than that obtained by the ACI building code. Thus, it is possible to state that the optical fiber sensor made it possible to determine the elastic modulus with good precision and similar to the electric strain gauge - the most used method to evaluate strain in structures. The FBG was the methodology that presented the median of the data distribution closest to its theoretical value, indicating good reliability. It is not known which measurement yields the correct results since all techniques adopted are an estimation of the measured parameter. Therefore, authors must state the method adopted in their research and take into consideration the influence of the boundary condition and sensor used.

Although there is a variation in the aggregate and cement properties, it was possible to find in the literature a $35 \mathrm{GPa}$ static modulus of mortars with the same mix design used in this paper [13], [77], [78].

\section{Dynamic modulus}

To calculate the dynamic elastic modulus, the mortar beams were excited and the damped vibration signal was recorded over time. This signal, after processed (fast Fourier transform - FFT), allowed the verification of the dominant frequencies, referring to how many oscillations the beam suffered in the interval equivalent to one second. The damped vibration spectrum over time and the frequency domain spectrum of the performed tests are shown in Figure 11 to Figure 14. 


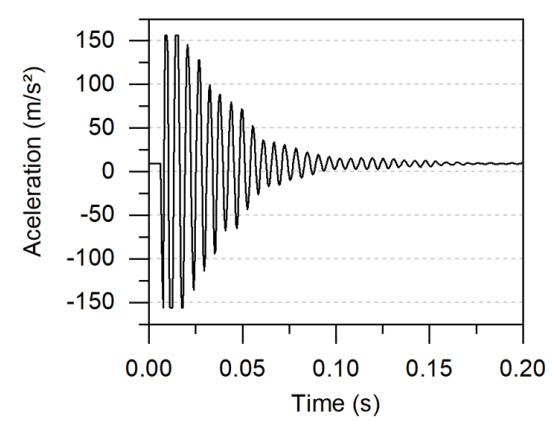

(a)

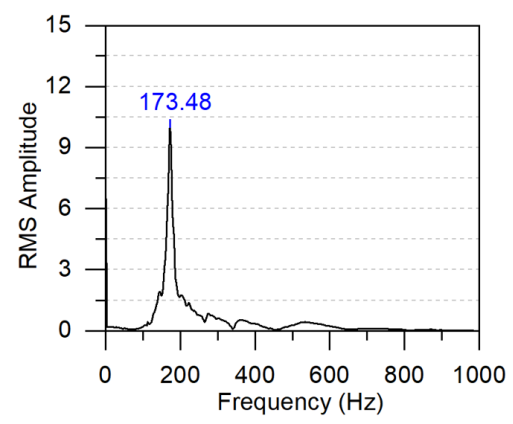

(b)

Figure 11. Accelerometer signal in (a) time and (b) frequency domain

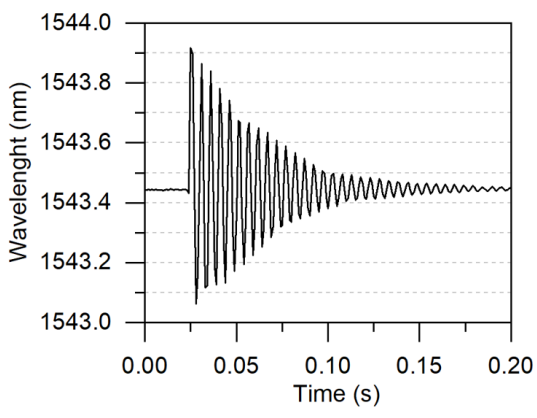

(a)

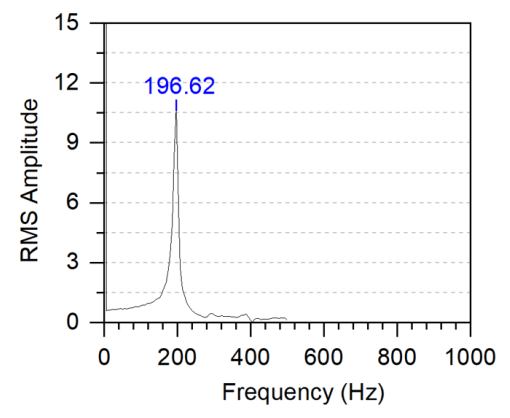

(b)

Figure 12. FBG signal in (a) time and (b) frequency domain

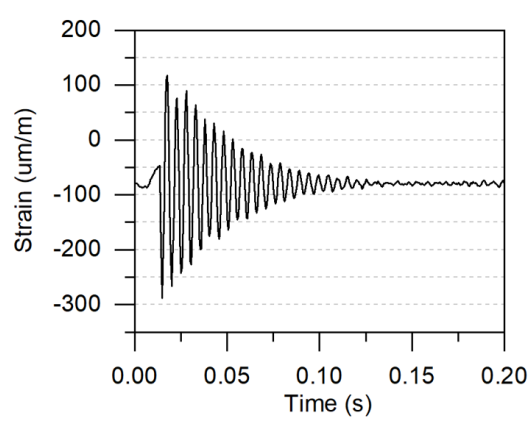

(a)

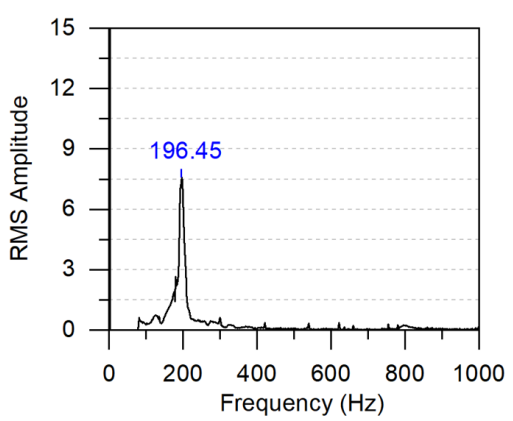

(b)

Figure 13. Strain gauge signal in (a) time and (b) frequency domain

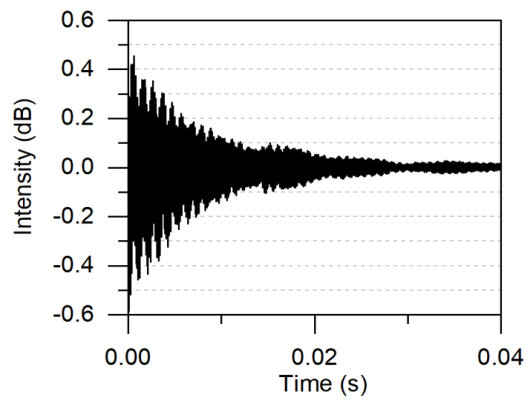

(a)

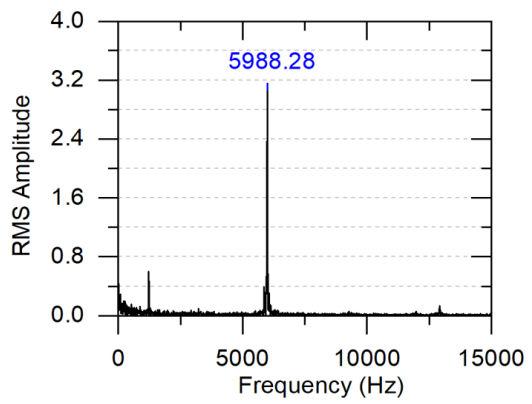

(b)

Figure 14. Microphone signal in (a) time and (b) frequency domain 
The obtained frequency is presented as a function of the root mean square (RMS) amplitude - a statistical measure of the magnitude of the sensor. From the results, it was possible to verify that all sensors allowed the acquisition of beam vibration with good precision (well-defined damping coefficient and frequency peak). For the microphone, a high frequency is observed since the sensor registered a sound wave and not strain measurements like the other sensors. Figure 15 shows the average values of the natural frequencies.

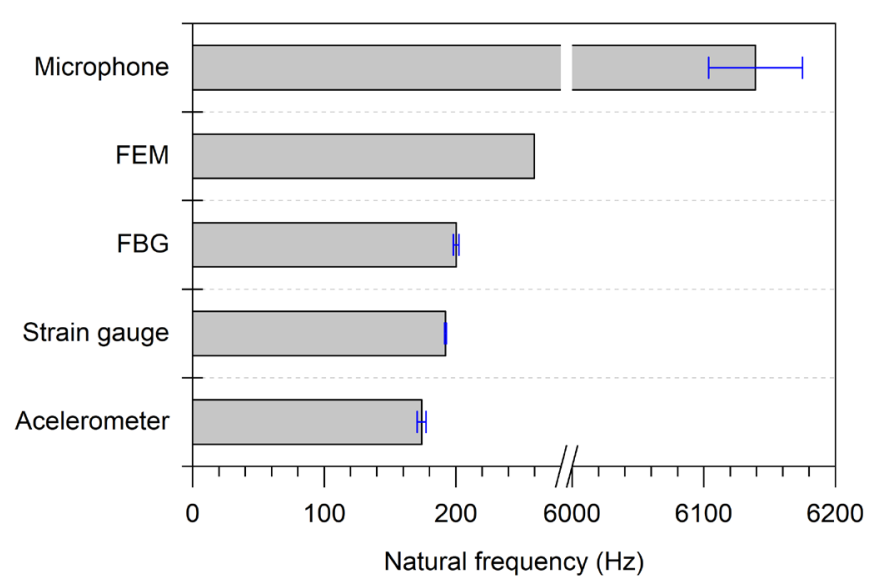

Figure 15. Natural resonant vibration frequencies

It is observed in Figure 15 that each sensor presented a distinct natural frequency of vibration. In the statistical analysis, the results obtained by the microphone were disregarded, since the obtained frequencies are in another order of magnitude $(\mathrm{kHz})$. After the ANOVA test, it was proved that the means are statistically different from each other and, therefore, the method/sensor used to measure the vibration influenced the frequencies obtained. It was also observed that only the FBG and strain gauge methods did not present statistically significant differences (Tukey with a $95 \%$ confidence level).

Thus, it is possible to state that the estimated theoretical frequency via FEM was the highest among the techniques used, due to the use of the elastic modulus estimated by ACI 318 [7]. The result obtained by the accelerometer was $33 \%$ lower than the estimated theoretical value via FEM. The average frequency value obtained by the FBG and the strain gauge were on average $25 \%$ lower than the theoretical value. Silva et al. [53], during dynamic tests, also verified no statistically significant differences between vibration frequencies in concrete and wood beams using strain gauge and FBG. Since the natural vibration frequency depends on the geometry, it is not possible to compare the values obtained in this research with other works in the literature. By applying the logarithmic decrement method, according to Equation 7, it was possible to estimate the damping coefficient of the beam by the sensors (Figure 16).

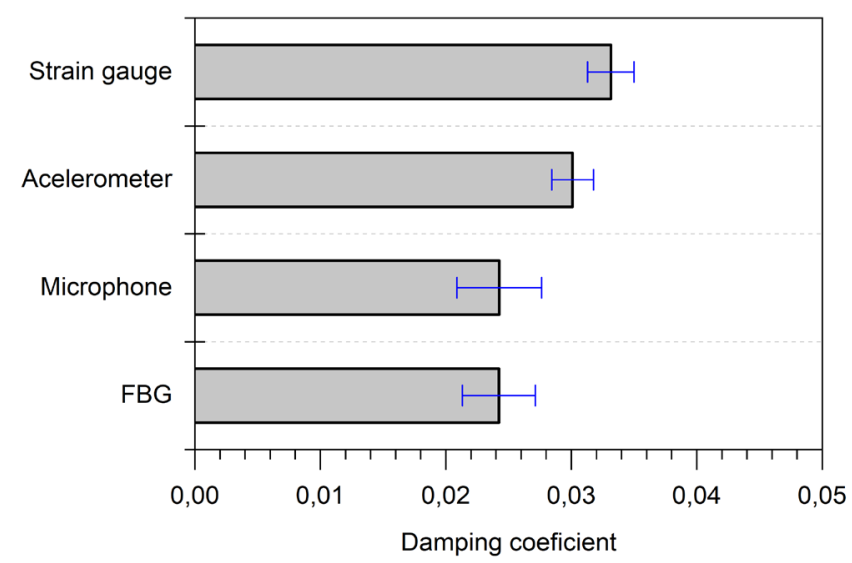

Figure 16. Sample damping coefficient 
After the ANOVA test at a significance level of 0.05 , no significant differences were found between the means obtained. Therefore, the type of sensor used did not influence the material damping coefficient measurement, which presented an average of 0.0279 .

Since the damping coefficient is an intrinsic property of the material, as it is the elastic modulus, and does not depend on the geometry of the structural element, it can be verified that the obtained value is similar to what was found by other authors. In mortar specimens, Gidrão [13] observed damping coefficients from 0.02 to 0.14 and Swamy and Rigby [79] between 0.02 and 0.15 . After signal acquisition and processing, the dynamic elastic modulus of the beams was calculated. Figure 17 presents the obtained values for the dynamic elastic modulus.

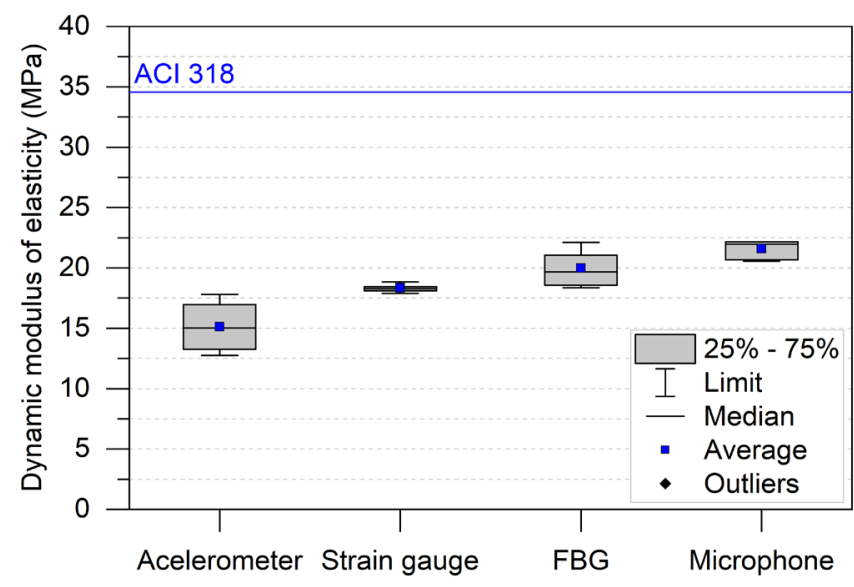

Figure 17. Dynamic elastic modulus of the mortar beam

From the results of the statistical analysis (ANOVA) it is possible to conclude that, at a confidence level of 0.05 , there are significant differences between the means of the used methods. In the Tukey test, the results obtained by the FBG and the strain gauge are not statistically different. This finding highlights the accuracy in detecting the natural vibration frequency and the elastic modulus obtained by the optical fiber sensor (FBG) and proves the feasibility of its use in the monitoring of concrete structures.

The dynamic elastic modulus for the same mortar beams ranged from 15.12 to $23.42 \mathrm{GPa}$, and all results were below the estimated value by ACI 318 [7] of $34.06 \mathrm{GPa}$. When compared with the static modulus obtained by FBG, the same method for the dynamic test showed an average reduction of $40 \%$ in the values. The pulse velocity tends to reduce slightly as the length decreases due to the increased attenuation of higher frequency components [80]. Therefore, the lower values for the dynamic elastic module could be explained by the length of the specimen which did not affect the static measurements. So, this behavior must be considered during inspections of slender or long members since low elastic module values could be obtained due to the sample geometry.

\section{CONCLUSIONS}

Different methods are used in this paper to obtain the same properties of a material. The research presents a state of the art on methods and sensors for structural experimental analysis. From the results obtained in the study of the static and dynamic modulus of mortar beams by different methods, it can be concluded that:

- The results show how the sensor and technique adopted can influence the final results, Thence, it is essential that published papers state the details on their experiment and take the sensor and boundary conditions into consideration during their analysis.

- FBG sensor had a sensitivity of $1.2180 \mathrm{pm} / \mu \mathrm{m} / \mathrm{m}$, with an adjusted $\mathrm{R}^{2}$ of 0.9989 , result $0.31 \%$ higher than the theoretical adjustment. Overall, the optical fiber sensor (FBG) presented a good precision for measuring strain, natural vibration frequency, damping coefficient and elastic modulus (static and dynamic) of the mortar.

- There is a nonlinear behavior of the vertical displacement of the beam acquired by the dial indicator in the static test, which underestimated $10 \%$ the elastic modulus values of the material. And it was proved that the theoretical model proposed by the American Concrete Institute (ACI) to calculate the static elastic modulus of concrete is reliable 
- The type of sensor/method did not influence the material damping coefficient measurement, which presented an average of 0.0279 . Although the results are consistent, further investigations are required to evaluate how this property can be influenced by the material and its geometry.

- There were no significant differences between the static and dynamic elastic modulus obtained by the FBG and the strain gauge. Therefore, the optical fiber sensor (FBG) presented a high accuracy in the detection of the strain, natural vibration frequency, damping coefficient and elastic modulus of the mortar beams and could be used for structural instrumentation.

- When compared with the static modulus obtained by FBG, the same method for the dynamic test showed an average reduction of $40 \%$ in the values due to the length of the specimen which only affected the dynamic measurements.

\section{ACKNOWLEDGMENTS}

The authors thank PPGECC and CESEC at UFPR, as well as the Multi-User Photonics Facility at UTFPR-CT, for the provided equipment.

\section{REFERENCES}

[1] B. Zech and M. J. Setzer, "The dyamic modulus of hardened cement paste. Part 2: ice formation, drying and pore size distribution," Mater. Struct., vol. 22, no. 2, pp. 125-132, Mar 1989.

[2] B. Zech and M. J. Setzer, "The dynamic elastic modulus of hardened cement paste. Part I: a new statistical model-water and ice filled pores," Mater. Struct., vol. 21, no. 5, pp. 323-328, Sep 1988.

[3] A. Alsalman, C. N. Dang, G. S. Prinz, and W. M. Hale, "Evaluation of modulus of elasticity of ultra-high performance concrete," Constr. Build. Mater., vol. 153, pp. 918-928, Oct 2017.

[4] M. Alves, G. L. Andreatta, G. Macioski, and A. Medeiros, "Efeito da substituição da água de amassamento por gelo nas propriedades de concretos C30 e C70," in An. 59 Cong. Bras. Concr., 2017.

[5] A. Behnood, J. Olek, and M. A. Glinicki, "Predicting modulus elasticity of recycled aggregate concrete using M5' model tree algorithm," Constr. Build. Mater., vol. 94, pp. 137-147, Sep 2015.

[6] P. C. C. Hewlett, Lea's Chemistry of Cement and Concrete, 5th ed. Oxford: Butterworth-Heinemann Elsevier, 2003.

[7] American Concrete Institute, Building Code Requirements for Structural Concrete, ACI 318, 2014, p. 524.

[8] S. Mindess, J. F. Young, and D. Darwin, Concrete, 2nd ed. Upper Saddle River: Prentice Hall, 2003.

[9] K. J. Bastgen and V. Hermann, "Experience made in determining the static modulus of elasticity of concrete," Materiaux Constructions, vol. 10, no. 6, pp. 357-364, Nov 1977.

[10] American Society for Testing Materials, Standard Test Method for Static Modulus of Elasticity and Poisson's Ratio of Concrete in Compression, ASTM C469, 2014, p. 5.

[11] S. Han and J. Kim, "Effect of temperature and age on the relationship between dynamic and static elastic modulus of concrete," Cement Concr. Res., vol. 34, no. 7, pp. 1219-1227, 2004.

[12] B. D. Liu, W. J. Lv, L. Li, and P. F. Li, "Effect of moisture content on static compressive elasticity modulus of concrete," Constr. Build. Mater., vol. 69, pp. 133-142, 2014.

[13] G. M. S. Gidrão, "Propriedades dinâmicas do concreto e relações com sua microestrutura,” M.S. thesis, Esc. Eng. São Carlos, Univ. São Paulo, 2015.

[14] Y. Zhou, J. Gao, Z. Sun, and W. Qu, "A fundamental study on compressive strength, static and dynamic elastic moduli of young concrete," Constr. Build. Mater., vol. 98, pp. 137-145, 2015.

[15] D. Kocab, B. Kucharczykova, P. Misak, P. Zitt, and M. Kralikova, "Development of the Elastic Modulus of Concrete under Different Curing Conditions," Procedia Eng., vol. 195, pp. 96-101, 2017.

[16] J. M. L. Reis, L. C. S. Nunes, A. L. C. Triques, L. C. G. Valente, and A. M. B. Bragaa, "Mechanical characterization using optical fiber sensors of polyester polymer concrete made with recycled aggregates," Mater. Res., vol. 12, no. 3, pp. 269-271, 2009.

[17] A. Castro-Caicedo, P. Toores, and R. Lain, "Packaging and testing of fiber Bragg gratings for use as strain sensor in rock specimens," in Proc. 8th Iberoam Opt Meeting and 11th Latin Am. Meeting Opt, Lasers Appl., vol. 8785, no. 1, p. 7, 2013.

[18] A. Othonos, "Fiber Bragg gratings," Rev. Sci. Instrum., vol. 68, no. 12, pp. 4309, 1998.

[19] R. K. Mobley, An Introduction to Predictive Maintenance. Amsterdam: Butterworth-Heinemann, 2002.

[20] P. J. M. Monteiro, P. R. L. Helene, and S. H. Kang, "Designing concrete mixtures for strength, elastic modulus and fracture energy," Mater. Struct., vol. 26, no. 8, pp. 443-452, Oct 1993. 
[21] P. K. Mehta and P. J. M. Monteiro, Concrete - Microstructure, Properties, and Materials, 4th ed. Berkeley: McGraw-Hill Education, 2013.

[22] American Society for Testing Materials, Standard Test Method for Pulse Velocity Through Concrete, ASTM C597, 2009 , p. 4.

[23] N. G. Silva and C. C. Campiteli, "Correlação entre módulo de elasticidade dinâmico e resistências mecânicas de argamassas de cimento, cal e areia," Ambient. Constr., vol. 8, no. 4, pp. 21-35, 2008.

[24] American Society for Testing Materials, Fundamental Transverse, Longitudinal, and Torsional Resonant Frequencies of Concrete Specimens, ASTM C215, 2014, p. 7.

[25] American Society for Testing Materials, Standard Test Method for Dynamic Young's Modulus, Shear Modulus, and Poisson's Ratio by Sonic Resonance, ASTM E1875, 2008, p. 9.

[26] American Society for Testing Materials, Standard Test Method for Dynamic Young's Modulus, Shear Modulus, and Poisson's Ratio by Impulse Excitation of Vibration, ASTM E1876, 2015, p. 17.

[27] H. J. F. Diógenes, L. C. Cossolino, A. H. A. Pereira, M. K. El Debs, and A. L. H. C. El Debs, "Determination of modulus of elasticity of concrete from the acoustic response," Rev. IBRACON Estrut. Mater., vol. 4, no. 5, pp. 11, Oct 2011.

[28] J. Han, G. Pan, and W. Sun, "Elastic modulus change investigation of cement paste before and after carbonation using nanoindentation technique," Procedia Eng., vol. 27, pp. 341-347, 2012.

[29] W. Li, S. Kawashima, J. Xiao, D. J. Corr, C. Shi, and S. P. Shah, "Comparative investigation on nanomechanical properties of hardened cement paste," Mater. Struct., vol. 49, no. 5, pp. 1591-1604, 2016.

[30] D. C. S. Garcia, M. M. N. S. Soares, A. C. S. Bezerra, M. T. P. Aguilar, and R. B. Figueiredo, "Microstructure and hardness of cement pastes with mineral admixture," Materia, vol. 22, no. 2, 2017.

[31] E. Mousavi, A. Cheshomi, and M. Ashtari, "Estimating elasticity modulus and uniaxial compressive strength of sandstone using indentation test," J. Petrol. Sci. Eng., vol. 169, pp. 157-166, 2018.

[32] Y. Wang et al., "Determination of load-strain characteristics of concrete slabs by using embedded fiber Bragg grating sensors," in Proc. Fifth Eur. Conf. Smart Struct. Mater., 2000, vol. 4073, pp. 297-304.

[33] A. Quintela, C. Jauregui, J. Echevarra, and J. M. Lopez-Higuera, "Embedded temperature strain fibre Bragg grating sensor system validation for concrete structures," J. Opt. A, Pure Appl. Opt., vol. 4, no. 6, pp. S387-S390, Nov 2002.

[34] M. Majumder, T. K. Gangopadhyay, A. K. Chakraborty, K. Dasgupta, and D. K. Bhattacharya, "Fibre Bragg gratings in structural health monitoring: present status and applications," Sens. Actuators A Phys., vol. 147, no. 1, pp. 150-164, Sep 2008.

[35] C. Rodrigues, C. Félix, A. Lage, and J. Figueiras, "Development of a long-term monitoring system based on FBG sensors applied to concrete bridges," Eng. Struct., vol. 32, no. 8, pp. 1993-2002, 2010.

[36] M. Fajkus, J. Nedoma, P. Mec, M. Pinka, M. Novak, and S. Zabka, "Deformation sensor composed of fiber Bragg grating and the strain gauge for use in civil engineering," in Proc. Electro-Optical Remote Sens. XII, 2018, vol. 10796, pp. 34.

[37] P. Mec, M. Stolarik, S. Zabka, and M. Novak, "Application of FBG in the experimental measurements of structural elements deformation from cement composites," in Proc. Electro-Optical Remote Sens. XII, 2018, vol. 10796, pp. 29.

[38] V. Saouma and L. Perotti, "Constitutive model for alkali-aggregate reactions," ACI Mater. J., vol. 103, no. 3, pp. 194-202, 2006.

[39] V. E. Saouma, D. Z. Anderson, K. Ostrander, B. Lee, and V. Slowik, "Application of fiber Bragg grating in local and remote infrastructure health monitoring," Mater. Struct., vol. 31, no. 4, pp. 259-266, 1998.

[40] G. Kaklauskas, A. Sokolov, R. Ramanauskas, and R. Jakubovskis, "Reinforcement strains in reinforced concrete tensile members recorded by strain gauges and FBG sensors: experimental and numerical analysis," Sensors, vol. 19, no. 1, 2019.

[41] J. Gao, J. Wu, J. Li, and X. Zhao, "Monitoring of corrosion in reinforced concrete structure using Bragg grating sensing," NDT Int., vol. 44, no. 2, pp. 202-205, Mar 2011.

[42] J. S. Leng and A. Asundi, "NDE of smart structures using multimode fiber optic vibration sensor," NDT Int., vol. 35, no. 1, pp. 45$51,2002$.

[43] J. R. Lee, H. Tsuda, and N. Toyama, "Impact wave and damage detections using a strain-free fiber Bragg grating ultrasonic receiver," NDT Int., vol. 40, no. 1, pp. 85-93, 2007.

[44] C. C. Chen, W. H. Wu, F. Shih, and S. W. Wang, "Scour evaluation for foundation of a cable-stayed bridge based on ambient vibration measurements of superstructure," NDT Int., vol. 66, pp. 16-27, 2014.

[45] A. Carrión, V. Genovés, J. Gosálbez, R. Miralles, and J. Payá, "Ultrasonic signal modality: a novel approach for concrete damage evaluation," Cement Concr. Res., vol. 101, pp. 25-32, Nov 2017.

[46] P. C. Chang, A. Flatau, and S. C. Liu, "Review paper: health monitoring of civil infrastructure," Struct. Health Monit. An Int. J., vol. 2, no. 3, pp. 257-267, Sep 2003.

[47] U. Dahlen, N. Ryden, and A. Jakobsson, "Damage identification in concrete using impact non-linear reverberation spectroscopy," NDT Int., vol. 75, pp. 15-25, Oct 2015. 
[48] Y. Farnam, M. R. Geiker, D. Bentz, and J. Weiss, "Acoustic emission waveform characterization of crack origin and mode in fractured and ASR damaged concrete," Cement Concr. Compos., vol. 60, pp. 135-145, Jul 2015.

[49] B. Glisic and D. Inaudi, Fibre Optic Methods for Structural Health Monitoring. Newport Beach: John Wiley \& Sons, 2007.

[50] G. Karaiskos, A. Deraemaeker, D. G. Aggelis, and D. V. Hemelrijck, "Monitoring of concrete structures using the ultrasonic pulse velocity method," Smart Mater. Struct., vol. 24, no. 11, pp. 113001, 2015.

[51] A. Khadour and J. Waeytens, "Monitoring of concrete structures with optical fiber sensors" in F. P. Torgal et al., Eds., Eco-Efficient Repair and Rehabilitation of Concrete Infrastructures. Duxford: Woodhead Publishing, Jan. 2018, pp. 97-121.

[52] E. Penner, “Avaliação de desempenho de sistemas estruturais de pontes de concreto,” Ph.D. dissertation, Esc. Politéc., Univ. São Paulo, 2001.

[53] J. C. C. Silva, C. Martelli, H. J. Kalinowski, E. Penner, J. Canning, and N. Groothoff, "Dynamic analysis and temperature measurements of concrete cantilever beam using fibre Bragg gratings," Opt. Lasers Eng., vol. 45, no. 1, pp. 88-92, Jan 2007.

[54] C. Frotté, C. S. A. di Nubila, A. Nagalli, W. Mazer, G. Macioski, and L. O. S. Oliveira, "Study of physical and mechanical concrete properties with partial replacement of natural aggregate by recycled aggregate from CDW," Rev. Materia, vol. 22, no. 2, e11811, 2017.

[55] M. Abdelrahman, M. K. ElBatanouny, P. Ziehl, J. Fasl, C. J. Larosche, and J. Fraczek, "Classification of alkali-silica reaction damage using acoustic emission: A proof-of-concept study," Constr. Build. Mater., vol. 95, pp. 406-413, Oct 2015.

[56] F. Mitschke, Fiber Optics: Physics and Technology, 2nd ed. Berlin: Springer, 2016.

[57] A. N. Chester, S. Martellucci, and A. M. V. Scheggi, Optical Fiber Sensors, 1st ed. California: Springer, 1987.

[58] R. Kashyap, Fiber Bragg Gratings, 2nd ed. Oxford: Academic Press, 2010.

[59] K. O. Hill, Y. Fujii, D. C. Johnson, and B. S. Kawasaki, "Photosensitivity in optical fiber waveguides: application to reflection filter fabrication," Appl. Phys. Lett., vol. 32, no. 10, pp. 647-649, May 1978.

[60] S. Yin, P. B. Ruffin, and F. T. S. Yu, Fiber Optic Sensors, 2nd ed. New Hampshire: CRC Press, 2008.

[61] C. A. J. Gouveia, J. M. Batista, and A. S. P. Jorge, "Refractometric optical fiber platforms for label free sensing," in Current Developments in Optical Fiber Technology, 1st ed., Rijeka: IntechOpen, 2013, p. 30.

[62] C. K. Y. Leung et al., "Review: optical fiber sensors for civil engineering applications," Mater. Struct., vol. 48, no. 4, pp. 871-906, Nov 2015.

[63] K. T. V. Grattan and B. T. Meggitt, Optical Fiber Sensor Technology: Devices and Technology, 1st ed. London: Springer US, 1998.

[64] S. Daud and J. Ali, Fibre Bragg Grating and No-Core Fibre Sensors, 1st ed. Switzerland: Springer, 2018.

[65] American Society for Testing Materials, Standard Specification for Portland Cement, ASTM C150, 2018 , p. 9.

[66] American Society for Testing Materials Standard Test Method for Relative Density (Specific Gravity) and Absorption of Fine Aggregate, ASTM C128, 2015, p. 6.

[67] American Society for Testing Materials, Standard Test Method for Sieve Analysis of Fine and Coarse Aggregates, ASTM C136, 2019 , p. 5.

[68] American Society for Testing Materials, Standard Test Method for Compressive Strength of Hydraulic Cement Mortars, ASTM C109, 2018, p. 9.

[69] American Society for Testing Materials, Standard Practice for Mechanical Mixing of Hydraulic Cement Pastes and Mortars of Plastic Consistency, ASTM C305, 2014, p. 3.

[70] American Society for Testing Materials, Standard Test Method for Compressive Strength of Cylindrical Concrete Specimens, ASTM C39, 2018.

[71] R. C. Hibbeler, Resistência dos Materiais, 7th ed. São Paulo: Pearson Universidades, 2009.

[72] L. C. Cossolino and A. H. A. Pereira, Relatório Técnico-Científico ITC04 Amortecimento: Classificação e Métodos de Determinação. São Paulo: ATCP, 2010, p. 14.

[73] W. Chen and X. Dong, "Modification of the wavelength-strain coefficient of FBG for the prediction of steel bar corrosion embedded in concrete," Opt. Fiber Technol., vol. 18, no. 1, pp. 47-50, Jan 2012.

[74] C. Li, H. Sun, and L. Li, "A review: the comparison between alkali-activated slag ( $\mathrm{Si}+\mathrm{Ca}$ ) and metakaolin ( $\mathrm{Si}+\mathrm{Al})$ cements," Cement Concr. Res., vol. 40, no. 9, pp. 1341-1349, 2010.

[75] A. Othonos and K. Kalli, Fiber Bragg Gratings - Fundamentals and Applications in Telecommunications and Sensing, 1st ed. Norwood: Artech House Print on Demand, 1999.

[76] F. C. Montija, “Aspectos da variabilidade experimental do ensaio de módulo de deformação do concreto,” M.S. thesis, Univ. São Paulo, São Paulo, 2007.

[77] M. R. G. Pena, "Estudo da fissuração associada à retração em argamassas para reparo em estruturas de concreto,” M.S. thesis, Esc. Politéc., Univ. São Paulo, 2004. 
[78] G. Macioski, L. A. Martins, T. Mueller, and A. Matoski, "Avaliação das propriedades de argamassas com adição de fibra de Curauá (Ananas Erectifolius)," Rev. Eng. Constr. Civ., vol. 3, no. 2, pp. 52-62, 2014.

[79] N. Swamy and G. Rigby, "Dynamic properties of hardened paste, mortar and concrete," Materiaux Constructions, vol. 4, no. 1, pp. 13-40, 1971.

[80] IAEA, Guidebook on Non-Destructive Testing of Concrete Structures, 2002.

Author contributions: GM: conceptualization, methodology, data acquisition, analysis, writing; VO: data acquisition, writing; MHFM: supervision, writing.

Editors: Vladimir Guilherme Haach, Guilherme Aris Parsekian. 